\title{
Optimization of Conditions for High Concentration of Eleutheroside $E$ and Chlorgenic Acid Components of Acanthopanax koreanum Stem Extract
}

\author{
Sung Gi Kim ${ }^{1, \S, *}$, Byung Wook Yang ${ }^{2, \S, *}$, Jae Bum Lee ${ }^{1, *}$, Sa Hyun Kim ${ }^{3, \uparrow, * *}$ \\ and Sung Kwon Ko ${ }^{1, ;, * *}$ \\ ${ }^{I}$ Department of Oriental Medical Food \& Nutrition, Semyung University, Jecheon 27136, Korea \\ ${ }^{2}$ Leaders in Industry-university Cooperation + (LINC+), Semyung University, Jecheon 27136, Korea \\ ${ }^{3}$ Department of Clinical Laboratory Science, Semyung University, Jecheon 27136, Korea
}

This study was conducted to develop a new functional material by optimizing the conditions for high concentrations of chlorogenic acid and eleutheroside E in Acanthopanax koreanum stem. The total phenolic compound content was the highest in the 20 hours sonication Acanthopanax koreanum stem extract (UAK-20). In addition, eleutheroside E, a typical functional ingredient of Cortex Acanthopanacis, in the 20 hours treated Acanthopanax koreanum stem extract showed the highest content at $1.646 \%$. However, another functional ingredient, chlorogenic acid, showed the highest content of 2.625\% in 1 hour treated Acanthopanax koreanum stem extract. Therefore, it is considered that the optimal conditions for high concentrations of total phenolic compound and eleutheroside E are 20 hours sonication Acanthopanax koreanum stem extract.

Key Words: Sonication, Acanthopanax koreanum, Stem, Phenolic compound, Eleutheroside E, Chlorogenic acid

\section{서 론}

생약 오가피(五加皮)는 두릅나무과(오갈피나무과, Araliaceae) 오갈피속(Acanthopanax, Eleutherococcus) 식물로 동양 최고의 한의학서인 신농본초경에 처음으로 기재되었으며, 우리나라에서는 일반오갈피나무(Acanthopanax sessiliflorus) 또는 동속식물(두릅나무과 Araliaceae)의 뿌리 및 줄기 껍 질을 약전생약으로 사용하고 있다. 또한 중국약전에서는 세주오갈피나무(細柱五加皮, Acanthopanax gracilistylus), 가 시오갈피나무(Acanthopanax senticosus)가 수록되어 있다. 뿌리와 줄기 껍질을 식의약으로 사용하고 있으며(Yook,
2001), 한국에서 자생하는 Acanthopanax 속 식물은 15 종 으로 가시오갈피나무(A. senticosus), 민가시오갈피나무 $(A$. senticosus for. inernis), 왕가시오갈피나무(A. senticosus var. koreanus), 일반오갈피나무(A. sessiliflorus), 중부오갈피나 무(A. sessiliflorus for. chungbuensis), 지리산오갈피나무(A. chiisanense), 섬오갈피나무(A. koreanum), 개오갈피나무(A. divaricatus), 휜털오갈피나무(A. divaricatus var. albeofructus). 남부오갈피나무(A. divaricatus for. nambunensis), 수신오갈 피나무(A. divaricatus for. suchinmyunensis), 참오갈피나무(A. pedunculus), 당오갈피나무(A. sieboldianus), 서울오갈피나무 (A. seoulense), 털오갈피나무(A. rufinerve) 등이 있다(Yook, 1997). 중국 전역에서 약용되고 있는 오가피의 기원식물은

Received: October 30, 2020 / Revised: December 11, 2020 / Accepted: December 15, 2020

* Graduate student, ${ }^{* *}$ Professor.

${ }^{\S}$ These two authors contributed equally to this work.

${ }^{\dagger}$ Corresponding author: Sung Kwon Ko. Department of Oriental Medical Food \& Nutrition, Semyung University, Jecheon 27136, Korea.

Tel: +82-43-649-1433, Fax:+82-43-649-1759, e-mail: skko@semyung.ac.kr

${ }^{\dagger}$ Corresponding author: Sa-Hyun Kim. Department of Clinical Laboratory Science, Semyung University, Jaecheon 27136, Korea.

Tel: +82-43-649-1624, Fax:+82-50-4411-9604, e-mail: science4us@semyung.ac.kr

(C) The Korean Society for Biomedical Laboratory Sciences. All rights reserved.

(a) This is an Open Access article distributed under the terms of the Creative Commons Attribution Non-Commercial License (http://creativecommons.org/licenses/by-nc/3.0/) which permits unrestricted non-commercial use, distribution, and reproduction in any medium, provided the original work is properly cited. 
세주오갈피나무를 비롯한 그 동속식물인 가시오갈피나무 와 세잎오갈피나무(A. trifoliatus), 조엽오갈피나무(A. henryi), 오수유오갈피나무(A. evodiafolius) 등이 있다.

한방의학에서 인정하는 오가피의 효과로는 간장과 신 장의 기능을 정상화하고, 풍습으로 인한 관절통(風濕痺痛), 사지의 근맥(筋脈)이 땅기면서 뒤틀리는 것(四肢拘攣)을 다스리고, 관절을 구부리고 펴는 것이 어려운 증상(掘伸 不利)을 치료한다. 이와 같이 간장과 신장이 허하여 힘줄 과 뼈가 약해져서 다리를 쓰지 못하는데, 풍습으로 허리 와 무릎이 아픈데, 팔다리가 가늘어 지며 아픈데, 각기, 음위증, 여자의 음부소양증, 어린이의 걸음걸이가 늦어지 는데 쓴다. 그리고 방사선병의 예방치료와 신경통, 관절염, 관절류머티스 등에 사용한다(Korean Association of Pharmacognosy Professors, 2004; Korean Association of Herbal Medicine Professors, 1994; Ko, 2016).

한편, Acanthopanax 속 식물의 생리활성에 관한 연구로 는 면역 및 항암작용, 성기능 정상화작용, 당뇨 개선작 용, 간 장애 개선작용, 진정작용, 항 스트레스작용 등이 보고되었다(Ahn et al., 2013). 오가피 성분에 관한 연구는 Ovodov가 오가피의 근피 추출물에서 eleutheroside A, B, B$1, \mathrm{C}, \mathrm{D}, \mathrm{E}, \mathrm{G}, \mathrm{I}, \mathrm{K}, \mathrm{M}$ 등의 성분을 분리하여 보고(Ovodov et al., 1996; Ovodov and Frolova, 1971) 한 이후, lignan, coumarin, diterpene, triterpene, phenolic compound 등의 천연물질들이 잎 또는 열매에 풍부하게 함유되어 주목받고 있다. 특히 섬오가피는 연골파괴보호(Lim et al., 2017), 세포 노화감소 (Park and Bae, 2016), 염증반응억제(Wei et al., 2015), 면역 반응조절(Jung et al., 2013) 등의 효과를 나타낸다.

또한, 오가피의 주성분인 eleutheroside $\mathrm{E}$ 는 관절염 개선 작용(He et al., 2014), 2형 당뇨 개선작용(Ahn et al., 2013)을 나타내었으며, eleutheroside B (syringin)는 항암작용(Lall et al., 2015), 간장 보호작용(Gong et al., 2014), 항염증작용 (Song et al., 2010), 항피로작용(Li et al., 2008), 항당뇨작용 (Niu et al., 2008), 진통작용(Choi et al., 2004) 등이 보고되었 다. 또한, 오갈피나무속 식물의 열매와 잎의 페놀성 식물 화학 성분에 대한 비교연구(An et al., 2017; An et al., 2017)가 시행되었다.

그러나, 제주도의 특산 식물로서 섬오갈피나무는 성분 및 생리활성 연구는 일부 시행되었지만, 기능성 강화 조 성물 개발에 대한 연구는 체계적으로 이루어지지 않은 점 에 착안하여 본 연구는 섬오가피 줄기의 초음파 열융합 처리 시간 $\left(100^{\circ} \mathrm{C}\right)$ 에 따른 페놀성 성분의 함량을 비교분석 함으로써 생리활성 성분(eleutheroside B, chlorogenic acid,

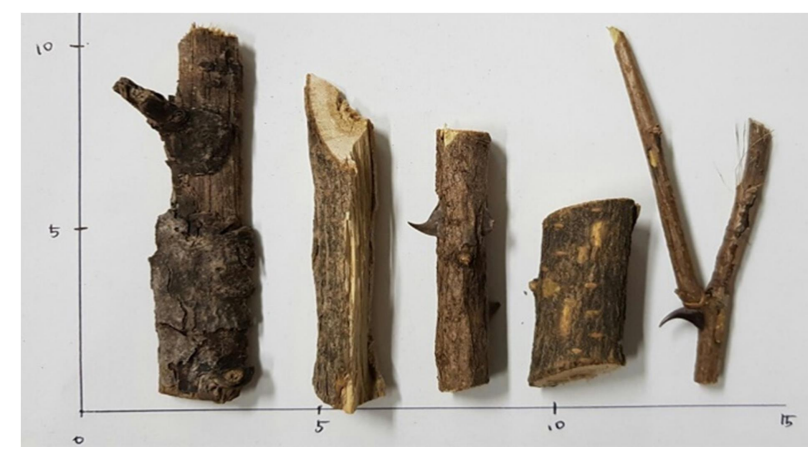

Fig. 1. The photograph of Acanthopanax koreanum stem (scale: cm). The Acanthopanax koreanum used in this study was collected on March 10, 2018 from the medicinal herb garden of the College of Pharmacy, Kyung Hee University.

eleutheroside E, syringaresinol, sinapyl alcohol) 고농도 함유 조성물과 전문화된 섬오가피 기능성 식품의 개발에 필요 한 기초 자료를 제공하고자 한다.

\section{재료 및 방법}

\section{실험재료}

본 연구에 사용한 섬오가피(Acanthopanax koreanum)는 경희대학교 약학대학 약초원에서 재배되고 있는 섬오가 피를 2018년 3월 10일에 채집하였으며, 채취한 섬오가피 를 온풍건조기(Dryer DS-501: 경동나비엔, 서울, 대한민국) 를 사용하여 $55^{\circ} \mathrm{C}$ 에서 72 시간 동안 건조하였다. 생약감별 은 경희대학교 약학대학 육창수 명예교수가 확인하였으 며, 제품표본은 세명대학교 기능식품소재개발 연구실에 보관하고 있다(Fig. 1).

\section{초음파 열융합 처리 섬오가피 엑스 조제}

섬오가피를 세절하고, 건조한 시료 $500 \mathrm{~g}$ 과 $15 \mathrm{~L}$ 의 증류 수를 초음파 처리기(출력 $1,200 \mathrm{~W}$, 주파수 $28 \mathrm{KHz}: \mathrm{KODO}$, 화성, 대한민국)에 넣고, $100^{\circ} \mathrm{C}$ 에서 1 (UAK-1), 2 (UAK-2), 3 (UAK-3), 4 (UAK-4), 5 (UAK-5), 6 (UAK-6), 7 (UAK-7), 8 (UAK-8), 9 (UAK-9), 10 (UAK-10), 11 (UAK-11), 12 (UAK12), 13 (UAK-13), 14 (UAK-14) 15 (UAK-15), 16 (UAK-16), 17 (UAK-17), 18 (UAK-18), 19 (UAK-19), 20 (UAK-20), 21 (UAK-21), 22 (UAK-22), 23 (UAK-23), 24 (UAK-24), 36 (UAK-36), 48 (UAK-48), 60 (UAK-60) 그리고 72 (UAK-72) 시간씩 1 회 추출 $(300 \mathrm{~mL})$ 하여 여과 후, 동결건조 하여 초 음파 열융합 처리 섬오가피 엑스를 얻었다. 


\section{$\mathrm{HPLC}-$ 성분의 분석}

Zhao 등의 방법(Zhao et al., 2014)에 따라 표준품과 직
접 비교하여 성분의 함량 및 조성을 각 시료당 3회 반 복 실험하여 결과의 재현성을 확인하여 분석하였다. 표 준품은 ChromaDex (Los Angeles, CA, U.S.A.)와 ChemFaces

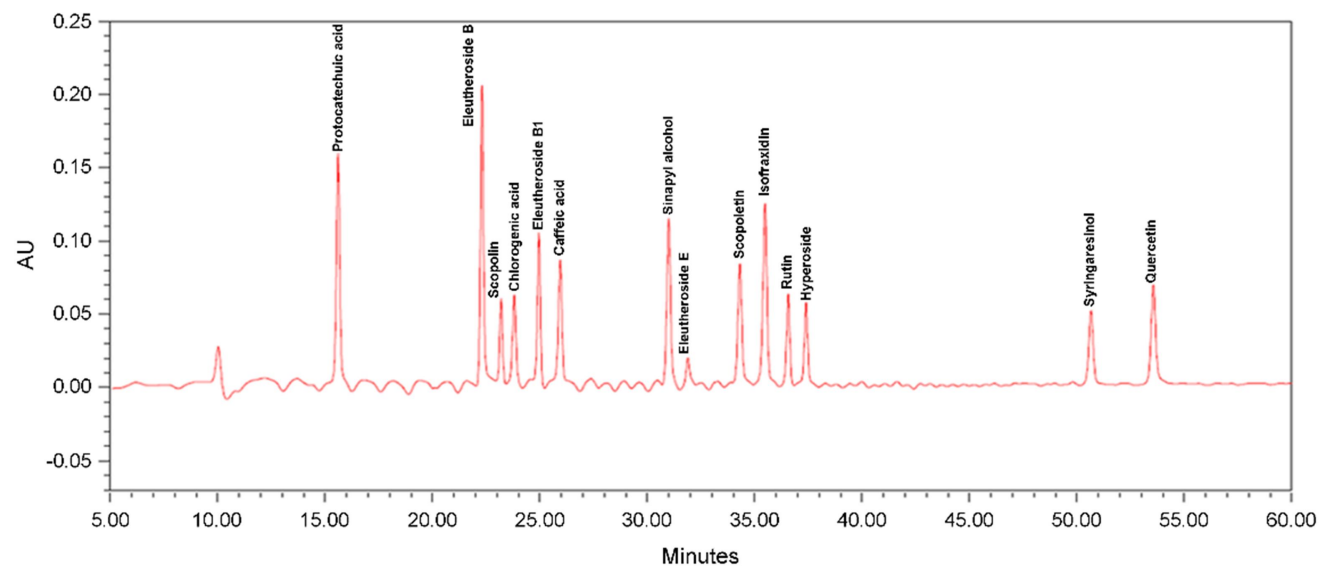

Mixed-Standards

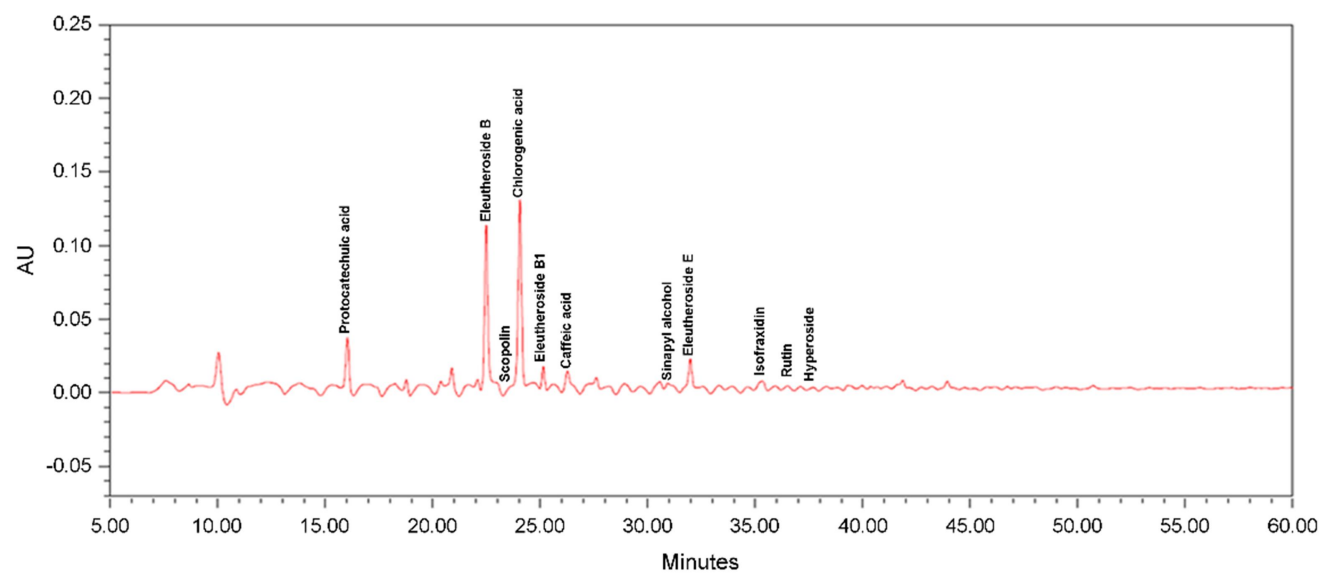

UAX-1

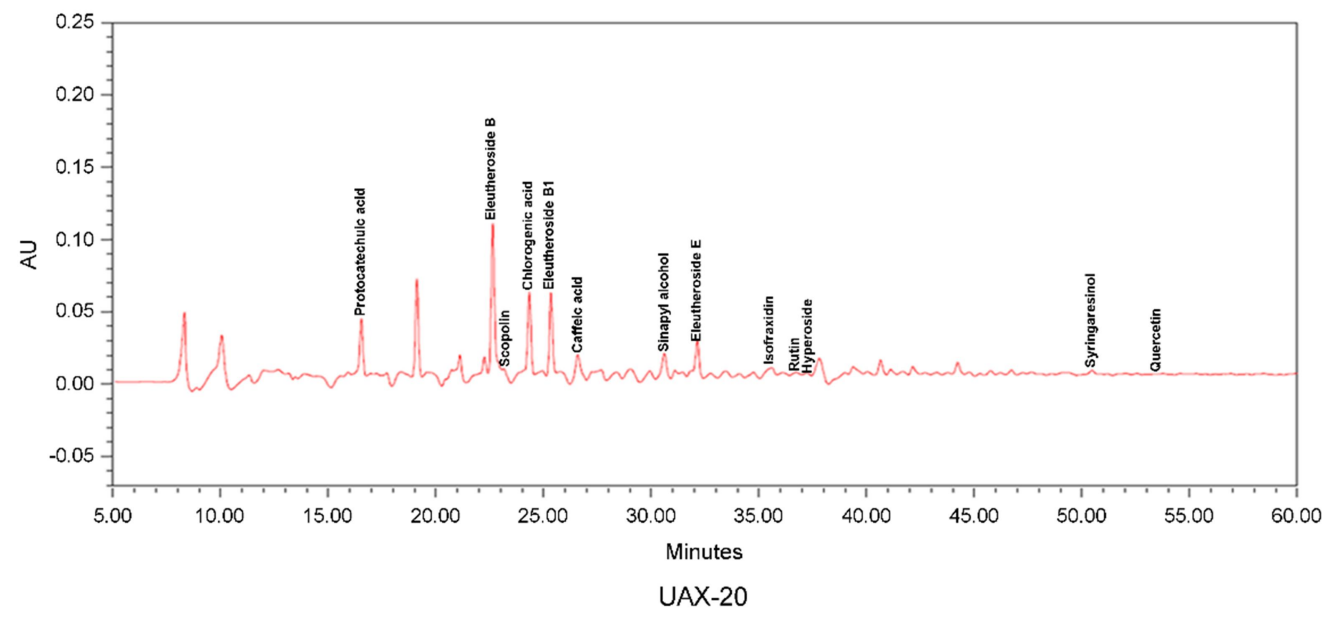

Fig. 2. HPLC chromatograms of various ultrasonic thermal fusion treated extracts of $\boldsymbol{A}$. koreanum stem. UAK-1: 1 hour ultrasonic thermal fusion treated extract, UAK-20: 20 hours ultra- sonic thermal fusion treated extract. 
(Wuhan, China)로부터 구입한 eleutheroside E, syringaresinol, eleutheroside B, chlorogenic acid, caffeic acid, protocatechuic acid, scopolin, isofraxidin, sinapyl alcohol, rutin, hyperoside를 사용하였다.

사용한 HPLC 장치는 Waters 1525 binary HPLC system (Milford, MA, U.S.A.)이며, 칼럼은 KNAUER Eurospher II 100-5 C18 (3×250 mm: Knauer, Born, Germany)을 사용하 였다. 이동상은 acetonitrile (HPLC grade; Sigma-Aldrich, U.S.A.)과 HPLC용 증류수 $(0.1 \%$ Trifluoroacetic acid, HPLC 급: B\&J, U.S.A.)이며, 페놀성 성분은 acetonitrile의 비율을 0\% (0 min)에서 7\% (10 min), 35\% (60 min), 100\% (65 min), 그리고 마지막으로 다시 $0 \%$ 로 조절하였고, 전개온도는 실온, 유속은 분당 $0.9 \mathrm{~mL}$, 크로마토그램은 UV 디텍터 (UV/Vis Waters 2487 Dual $\lambda$ Absorbance Detector: Milford, MA, U.S.A.)를 이용하여 $220 \mathrm{~nm}$ 에서 검출하였다(Fig. 2).

\section{결과 및 고찰}

섬오가피 줄기의 초음파 열융합 처리 $\left(100^{\circ} \mathrm{C}\right)$ 시간에 따 른 페놀성 성분의 함량변화를 비교분석 함으로서 생리활 성 성분 고농도 함유 조성물과 전문화된 섬오가피 기능 성 식품 소재 개발에 필요한 기초 자료를 제공하고자 본 연구를 실시하였으며, 섬오가피 생리활성 성분 고농도 함 유 조성물 탐색을 위한 성분분석은 중량 \%로 함량을 구 하였다.

총 페놀성 성분 함량에 있어서는 Table 1에서 보는 바 와 같이 20시간 초음파 열융합 처리(UAK-20)에서 6.661\% 로 가장 함량이 높았고, 그 다음으로 1 시간 초음파 열융 합 처리(UAK-1, 6.356\%) 그리고 4시간 초음파 열융합 처
리(UAK-4, 6.296\%)의 순서로 함량이 높았다.

오가피속 식물의 대표적인 주성분이며, 관절염 개선작 용(He et al., 2014), 2형 당뇨 개선작용(Ahn et al., 2013)을 나타내는 eleutheroside E는 20시간 초음파 열융합 처리 (UAK-20)에서 $1.646 \%$ 로 가장 함량이 높게 나타났고, 그 다음으로 4시간 초음파 열융합 처리(UAK-4, $1.522 \%$ ) 그리 고 16 시간 초음파 열융합 처리(UAK- $16,1.422 \%)$ 의 순서로 함량이 높았다.

또한, 항암작용(Lall et al., 2015), 간장 보호작용(Gong et al., 2014), 항염증작용(Song et al., 2010), 항피로작용(Li et al., 2008), 항당뇨작용(Niu et al., 2008), 진통작용(Choi et al., 2004) 등이 보고된 eleutheroside B (syringin)는 1시간 초음 파 열융합 처리(UAK-1)에서 $0.788 \%$ 로 가장 함량이 높게 나타났고, 그 다음으로 2시간 초음파 열융합 처리(UAK-2, $0.754 \%$ ) 그리고 5시간 초음파 열융합처리(UAK-5, 0.741\%) 의 순서로 함량이 높았다.

한편, chlorogenic acid는 1시간 초음파 열융합 처리(UAK1)에서 $2.625 \%$ 로 가장 함량이 높게 나타났고, 그 다음으 로 2 시간 초음파 열융합 처리(UAK-2, 2.116\%) 그리고 4시 간 초음파 열융합 처리(UAK-4, 1.942\%)의 순서로 함량이 높았다.

심근 세포 손상 및 사망 예방작용(Cho et al., 2015), 혈관 확장작용(Chung et al., 2012), 백혈병 암세포 증식억제(Park et al., 2008), H. pylori 운동성 억제(Miyazawa et al., 2006), 피부착색 및 노화방지(Kim et al., 2017) 등이 보고된 비 당체 성분인 syringaresinol은 8시간 초음파 열융합 처리 (UAK-8)에서부터 검출되기 시작해서 48 시간 초음파 열 융합 처리(UAK-48)에서 $0.152 \%$ 로 가장 함량이 높게 나 타났고, 그 다음으로 60 시간 초음파 열융합 처리(UAK-

Table 1. The phenolic compounds according to various ultrasonic thermal fusion treatment conditions of Acanthopanax koreanum stem

\begin{tabular}{|c|c|c|c|c|c|c|c|c|c|c|}
\hline $\begin{array}{l}\text { Phenolic } \\
\text { compounds }\end{array}$ & $\begin{array}{l}\text { Retention } \\
\text { time (min) }\end{array}$ & $\begin{array}{c}\text { Calibration } \\
\text { curves }^{1)}\end{array}$ & $R^{2}$ & UAK-1 & UAK-2 & UAK-3 & UAK-4 & UAK-5 & UAK-6 & UAK-7 \\
\hline $\begin{array}{l}\text { Protocatechuic } \\
\text { acid }\end{array}$ & 15.6 & $y=1.8130 x-0.9382$ & 0.9996 & $\begin{array}{c}0.407 \\
\pm 0.009\end{array}$ & $\begin{array}{c}0.411 \\
\pm 0.016\end{array}$ & $\begin{array}{c}0.282 \\
\pm 0.003\end{array}$ & $\begin{array}{c}0.443 \\
\pm 0.024\end{array}$ & $\begin{array}{c}0.283 \\
\pm 0.012\end{array}$ & $\begin{array}{c}0.392 \\
\pm 0.021\end{array}$ & $\begin{array}{c}0.333 \\
\pm 0.002\end{array}$ \\
\hline $\begin{array}{l}\text { Eleutheroside } \\
\text { B }\end{array}$ & 22.3 & $y=1.2143 x-0.8239$ & 0.9927 & $\begin{array}{c}0.788 \\
\pm 0.046\end{array}$ & $\begin{array}{c}0.754 \\
\pm 0.017\end{array}$ & $\begin{array}{c}0.732 \\
\pm 0.001\end{array}$ & $\begin{array}{c}0.740 \\
\pm 0.027\end{array}$ & $\begin{array}{c}0.741 \\
\pm 0.027\end{array}$ & $\begin{array}{c}0.689 \\
\pm 0.003\end{array}$ & $\begin{array}{c}0.624 \\
\pm 0.018\end{array}$ \\
\hline Scopolin & 23.2 & $y=0.4992 x-0.0811$ & 0.9965 & $\begin{array}{c}0.179 \\
\pm 0.005\end{array}$ & $\begin{array}{c}0.185 \\
\pm 0.003\end{array}$ & $\begin{array}{c}0.151 \\
\pm 0.001\end{array}$ & $\begin{array}{c}0.297 \\
\pm 0.004\end{array}$ & $\begin{array}{c}0.246 \\
\pm 0.001\end{array}$ & $\begin{array}{c}0.314 \\
\pm 0.003\end{array}$ & $\begin{array}{c}0.297 \\
\pm 0.006\end{array}$ \\
\hline $\begin{array}{l}\text { Chlorogenic } \\
\text { acid }\end{array}$ & 23.8 & $y=0.6093 x-0.3830$ & 0.9979 & $\begin{array}{c}2.625 \\
\pm 0.139\end{array}$ & $\begin{array}{c}2.116 \\
\pm 0.119\end{array}$ & $\begin{array}{c}1.872 \\
\pm 0.007\end{array}$ & $\begin{array}{c}1.942 \\
\pm 0.041\end{array}$ & $\begin{array}{c}1.579 \\
\pm 0.038\end{array}$ & $\begin{array}{c}1.725 \\
\pm 0.008\end{array}$ & $\begin{array}{c}1.263 \\
\pm 0.005\end{array}$ \\
\hline $\begin{array}{l}\text { Eleutheroside } \\
\text { B1 }\end{array}$ & 25.0 & $y=1.0370 x-0.7058$ & 0.9942 & $\begin{array}{c}0.328 \\
\pm 0.080\end{array}$ & $\begin{array}{c}0.468 \\
\pm 0.067\end{array}$ & $\begin{array}{c}0.498 \\
\pm 0.004\end{array}$ & $\begin{array}{c}0.666 \\
\pm 0.013\end{array}$ & $\begin{array}{c}0.590 \\
\pm 0.019\end{array}$ & $\begin{array}{c}0.754 \\
\pm 0.001\end{array}$ & $\begin{array}{c}0.560 \\
\pm 0.011\end{array}$ \\
\hline
\end{tabular}


Table 1. The phenolic compounds according to various ultrasonic thermal fusion treatment conditions of Acanthopanax koreanum stem (Continued)

$(\%, \mathrm{w} / \mathrm{w})$

\begin{tabular}{|c|c|c|c|c|c|c|c|c|c|c|}
\hline $\begin{array}{l}\text { Phenolic } \\
\text { compounds }\end{array}$ & $\begin{array}{l}\text { Retention } \\
\text { time (min) }\end{array}$ & $\begin{array}{c}\text { Calibration } \\
\text { curves }^{1)}\end{array}$ & $R^{2}$ & UAK-1 & UAK-2 & UAK-3 & UAK-4 & UAK-5 & UAK-6 & UAK-7 \\
\hline Caffeic acid & 26.0 & $y=1.0766 x-0.6009$ & 0.9937 & $\begin{array}{c}0.237 \\
\pm 0.054\end{array}$ & $\begin{array}{c}0.274 \\
\pm 0.088\end{array}$ & $\begin{array}{c}0.188 \\
\pm 0.006\end{array}$ & $\begin{array}{c}0.267 \\
\pm 0.032\end{array}$ & $\begin{array}{c}0.325 \\
\pm 0.005\end{array}$ & $\begin{array}{c}0.237 \\
\pm 0.038\end{array}$ & $\begin{array}{c}0.238 \\
\pm 0.011\end{array}$ \\
\hline $\begin{array}{l}\text { Eleutheroside } \\
\text { E }\end{array}$ & 31.9 & $y=0.2096 x-0.1589$ & 0.9975 & $\begin{array}{c}1.365 \pm \\
0.088\end{array}$ & $\begin{array}{c}0.960 \\
\pm 0.207\end{array}$ & $\begin{array}{c}1.147 \\
\pm 0.009\end{array}$ & $\begin{array}{c}1.522 \\
\pm 0.046\end{array}$ & $\begin{array}{c}1.289 \\
\pm 0.009\end{array}$ & $\begin{array}{c}1.333 \\
\pm 0.020\end{array}$ & $\begin{array}{c}0.870 \\
\pm 0.011\end{array}$ \\
\hline Sinapyl alcohol & 31.0 & $y=1.0216 x-0.4384$ & 0.9997 & $\begin{array}{c}0.081 \\
\pm 0.002\end{array}$ & $\begin{array}{c}0.064 \\
\pm 0.001\end{array}$ & $\begin{array}{c}0.106 \\
\pm 0.002\end{array}$ & $\begin{array}{c}0.103 \\
\pm 0.000\end{array}$ & $\begin{array}{c}0.094 \\
\pm 0.001\end{array}$ & $\begin{array}{c}0.070 \\
\pm 0.001\end{array}$ & $\begin{array}{c}0.082 \\
\pm 0.001\end{array}$ \\
\hline Rutin & 36.6 & $y=0.5647 x-0.2888$ & 0.9937 & $\begin{array}{c}0.191 \\
\pm 0.028\end{array}$ & $\begin{array}{c}0.128 \\
\pm 0.001\end{array}$ & $\begin{array}{c}0.141 \\
\pm 0.002\end{array}$ & $\begin{array}{c}0.149 \\
\pm 0.002\end{array}$ & $\begin{array}{c}0.151 \\
\pm 0.002\end{array}$ & $\begin{array}{c}0.161 \\
\pm 0.001\end{array}$ & $\begin{array}{c}0.227 \\
\pm 0.003\end{array}$ \\
\hline Hyperoside & 37.4 & $y=0.5531 x-0.2888$ & 0.9981 & $\begin{array}{c}0.167 \\
\pm 0.036\end{array}$ & $\begin{array}{c}0.079 \\
\pm 0.002\end{array}$ & $\begin{array}{c}0.149 \\
\pm 0.000\end{array}$ & $\begin{array}{c}0.093 \\
\pm 0.001\end{array}$ & $\begin{array}{c}0.117 \\
\pm 0.002\end{array}$ & $\begin{array}{c}0.126 \\
\pm 0.003\end{array}$ & $\begin{array}{c}0.208 \\
\pm 0.001\end{array}$ \\
\hline Isofraxidin & 35.5 & $y=1.3999 x-0.8996$ & 0.9950 & $\begin{array}{c}0.154 \\
\pm 0.012\end{array}$ & $\begin{array}{c}0.128 \\
\pm 0.007\end{array}$ & $\begin{array}{c}0.120 \\
\pm 0.000\end{array}$ & $\begin{array}{c}0.166 \\
\pm 0.020\end{array}$ & $\begin{array}{c}0.137 \\
\pm 0.006\end{array}$ & $\begin{array}{c}0.163 \\
\pm 0.003\end{array}$ & $\begin{array}{c}0.165 \\
\pm 0.001\end{array}$ \\
\hline Syringaresinol & 50.7 & $y=0.6778 x-0.3761$ & 0.9992 & - & - & - & - & - & - & - \\
\hline Quercetin & 53.6 & $y=0.8872 x-0.8803$ & 0.9939 & - & - & - & - & - & - & - \\
\hline $\begin{array}{l}\text { Total phenolic } \\
\text { compound }\end{array}$ & - & - & - & 6.356 & 5.486 & 5.237 & 6.296 & 5.437 & 5.838 & 4.659 \\
\hline
\end{tabular}

1) $\mathrm{y}$ : area units, $\mathrm{x}$ : concentration in standard solutions (ppm), *UAK-1: 1 hour ultrasonic thermal fusion treated extract of the Acanthopanax koreanum stem UAK-2: 2 hours ultrasonic thermal fusion treated extract, UAK-3: 3 hours ultrasonic thermal fusion treated extract, UAK-4: 4 hours ultrasonic thermal fusion treated extract, UAK-5: 5 hours ultrasonic thermal fusion treated extract, UAK-6: 6 hours ultrasonic thermal fusion treated extract, UAK-7: 7 hours ultrasonic thermal fusion treated extract, Values represent the mean \pm S.D. $(n=3)$

\begin{tabular}{|c|c|c|c|c|c|c|c|c|c|c|c|}
\hline $\begin{array}{l}\text { Phenolic } \\
\text { compounds }\end{array}$ & UAK-8 & UAK-9 & UAK-10 & UAK-11 & UAK-12 & UAK-13 & UAK-14 & UAK-15 & UAK-16 & UAK-17 & UAK-18 \\
\hline $\begin{array}{l}\text { Protocatechuic } \\
\text { acid }\end{array}$ & $\begin{array}{c}0.359 \\
\pm 0.001\end{array}$ & $\begin{array}{c}0.372 \\
\pm 0.001\end{array}$ & $\begin{array}{c}0.418 \\
\pm 0.001\end{array}$ & $\begin{array}{c}0.350 \\
\pm 0.001\end{array}$ & $\begin{array}{c}0.285 \\
\pm 0.003\end{array}$ & $\begin{array}{c}0.367 \\
\pm 0.000\end{array}$ & $\begin{array}{c}0.324 \\
\pm 0.001\end{array}$ & $\begin{array}{c}0.378 \\
\pm 0.002\end{array}$ & $\begin{array}{c}0.276 \\
\pm 0.002\end{array}$ & $\begin{array}{c}0.351 \\
\pm 0.000\end{array}$ & $\begin{array}{c}0.296 \\
\pm 0.002\end{array}$ \\
\hline $\begin{array}{l}\text { Eleutheroside } \\
\text { B }\end{array}$ & $\begin{array}{c}0.586 \\
\pm 0.002\end{array}$ & $\begin{array}{c}0.646 \\
\pm 0.007\end{array}$ & $\begin{array}{c}0.624 \\
\pm 0.001\end{array}$ & $\begin{array}{c}0.688 \\
\pm 0.006\end{array}$ & $\begin{array}{c}0.737 \\
\pm 0.001\end{array}$ & $\begin{array}{c}0.578 \\
\pm 0.001\end{array}$ & $\begin{array}{c}0.449 \\
\pm 0.002\end{array}$ & $\begin{array}{c}0.705 \\
\pm 0.007\end{array}$ & $\begin{array}{c}0.605 \\
\pm 0.001\end{array}$ & $\begin{array}{c}0.545 \\
\pm 0.004\end{array}$ & $\begin{array}{c}0.627 \\
\pm 0.003\end{array}$ \\
\hline Scopolin & $\begin{array}{c}0.248 \\
\pm 0.003\end{array}$ & $\begin{array}{c}0.274 \\
\pm 0.001\end{array}$ & $\begin{array}{c}0.252 \\
\pm 0.001\end{array}$ & $\begin{array}{c}0.212 \\
\pm 0.002\end{array}$ & $\begin{array}{c}0.211 \\
\pm 0.002\end{array}$ & $\begin{array}{c}0.209 \\
\pm 0.005\end{array}$ & $\begin{array}{c}0.252 \\
\pm 0.002\end{array}$ & $\begin{array}{c}0.241 \\
\pm 0.001\end{array}$ & $\begin{array}{c}0.265 \\
\pm 0.001\end{array}$ & $\begin{array}{c}0.180 \\
\pm 0.001\end{array}$ & $\begin{array}{c}0.429 \\
\pm 0.002\end{array}$ \\
\hline $\begin{array}{l}\text { Chlorogenic } \\
\text { acid }\end{array}$ & $\begin{array}{c}0.889 \\
\pm 0.003\end{array}$ & $\begin{array}{c}1.256 \\
\pm 0.010\end{array}$ & $\begin{array}{c}1.344 \\
\pm 0.012\end{array}$ & $\begin{array}{c}0.978 \\
\pm 0.006\end{array}$ & $\begin{array}{c}0.907 \\
\pm 0.005\end{array}$ & $\begin{array}{c}0.931 \\
\pm 0.006\end{array}$ & $\begin{array}{c}0.413 \\
\pm 0.005\end{array}$ & $\begin{array}{c}1.099 \\
\pm 0.005\end{array}$ & $\begin{array}{c}1.150 \\
\pm 0.000\end{array}$ & $\begin{array}{c}0.626 \\
\pm 0.002\end{array}$ & $\begin{array}{c}0.883 \\
\pm 0.009\end{array}$ \\
\hline $\begin{array}{l}\text { Eleutheroside } \\
\text { B1 }\end{array}$ & $\begin{array}{c}0.477 \\
\pm 0.002\end{array}$ & $\begin{array}{c}0.755 \\
\pm 0.011\end{array}$ & $\begin{array}{c}0.608 \\
\pm 0.004\end{array}$ & $\begin{array}{c}0.708 \\
\pm 0.009\end{array}$ & $\begin{array}{c}0.494 \\
\pm 0.011\end{array}$ & $\begin{array}{c}0.579 \\
\pm 0.015\end{array}$ & $\begin{array}{c}0.406 \\
\pm 0.006\end{array}$ & $\begin{array}{c}0.652 \\
\pm 0.003\end{array}$ & $\begin{array}{c}0.745 \\
\pm 0.000\end{array}$ & $\begin{array}{c}0.420 \\
\pm 0.004\end{array}$ & $\begin{array}{c}0.659 \\
\pm 0.003\end{array}$ \\
\hline Caffeic acid & $\begin{array}{c}0.266 \\
\pm 0.006\end{array}$ & $\begin{array}{c}0.269 \\
\pm 0.003\end{array}$ & $\begin{array}{c}0.197 \\
\pm 0.001\end{array}$ & $\begin{array}{c}0.183 \\
\pm 0.000\end{array}$ & $\begin{array}{c}0.322 \\
\pm 0.003\end{array}$ & $\begin{array}{c}0.236 \\
\pm 0.001\end{array}$ & $\begin{array}{c}0.146 \\
\pm 0.001\end{array}$ & $\begin{array}{c}0.399 \\
\pm 0.003\end{array}$ & $\begin{array}{c}0.221 \\
\pm 0.000\end{array}$ & $\begin{array}{c}0.228 \\
\pm 0.001\end{array}$ & $\begin{array}{c}0.166 \\
\pm 0.002\end{array}$ \\
\hline $\begin{array}{l}\text { Eleutheroside } \\
\text { E }\end{array}$ & $\begin{array}{c}1.170 \\
\pm 0.004\end{array}$ & $\begin{array}{c}1.291 \\
\pm 0.006\end{array}$ & $\begin{array}{c}0.944 \\
\pm 0.006\end{array}$ & $\begin{array}{c}1.331 \\
\pm 0.004\end{array}$ & $\begin{array}{c}1.114 \\
\pm 0.002\end{array}$ & $\begin{array}{c}0.862 \\
\pm 0.003\end{array}$ & $\begin{array}{c}0.471 \\
\pm 0.009\end{array}$ & $\begin{array}{c}1.100 \\
\pm 0.005\end{array}$ & $\begin{array}{c}1.422 \\
\pm 0.006\end{array}$ & $\begin{array}{c}0.917 \\
\pm 0.017\end{array}$ & $\begin{array}{c}1.010 \\
\pm 0.002\end{array}$ \\
\hline Sinapyl alcohol & $\begin{array}{c}0.102 \\
\pm 0.001\end{array}$ & $\begin{array}{c}0.104 \\
\pm 0.001\end{array}$ & $\begin{array}{c}0.115 \\
\pm 0.001\end{array}$ & $\begin{array}{c}0.138 \\
\pm 0.001\end{array}$ & $\begin{array}{c}0.230 \\
\pm 0.002\end{array}$ & $\begin{array}{c}0.175 \\
\pm 0.000\end{array}$ & $\begin{array}{c}0.147 \\
\pm 0.001\end{array}$ & $\begin{array}{c}0.182 \\
\pm 0.001\end{array}$ & $\begin{array}{c}0.091 \\
\pm 0.000\end{array}$ & $\begin{array}{c}0.158 \\
\pm 0.001\end{array}$ & $\begin{array}{c}0.156 \\
\pm 0.002\end{array}$ \\
\hline Rutin & $\begin{array}{c}0.175 \\
\pm 0.001\end{array}$ & $\begin{array}{c}0.179 \\
\pm 0.001\end{array}$ & $\begin{array}{c}0.170 \\
\pm 0.000\end{array}$ & $\begin{array}{c}0.167 \\
\pm 0.004\end{array}$ & $\begin{array}{c}0.295 \\
\pm 0.004\end{array}$ & $\begin{array}{c}0.206 \\
\pm 0.001\end{array}$ & $\begin{array}{c}0.176 \\
\pm 0.001\end{array}$ & $\begin{array}{c}0.205 \\
\pm 0.005\end{array}$ & $\begin{array}{c}0.143 \\
\pm 0.001\end{array}$ & $\begin{array}{c}0.179 \\
\pm 0.001\end{array}$ & $\begin{array}{c}0.262 \\
\pm 0.001\end{array}$ \\
\hline Hyperoside & $\begin{array}{c}0.151 \\
\pm 0.000\end{array}$ & $\begin{array}{c}0.145 \\
\pm 0.001\end{array}$ & $\begin{array}{c}0.164 \\
\pm 0.001\end{array}$ & $\begin{array}{c}0.124 \\
\pm 0.002\end{array}$ & $\begin{array}{c}0.244 \\
\pm 0.002\end{array}$ & $\begin{array}{c}0.197 \\
\pm 0.009\end{array}$ & $\begin{array}{c}0.152 \\
\pm 0.002\end{array}$ & $\begin{array}{c}0.212 \\
\pm 0.004\end{array}$ & $\begin{array}{c}0.082 \\
\pm 0.000\end{array}$ & $\begin{array}{c}0.172 \\
\pm 0.000\end{array}$ & $\begin{array}{c}0.220 \\
\pm 0.011\end{array}$ \\
\hline Isofraxidin & $\begin{array}{c}0.140 \\
\pm 0.001\end{array}$ & $\begin{array}{c}0.136 \\
\pm 0.002\end{array}$ & $\begin{array}{c}0.128 \\
\pm 0.000\end{array}$ & $\begin{array}{c}0.148 \\
\pm 0.000\end{array}$ & $\begin{array}{c}0.107 \\
\pm 0.000\end{array}$ & $\begin{array}{c}0.098 \\
\pm 0.000\end{array}$ & $\begin{array}{c}0.086 \\
\pm 0.001\end{array}$ & $\begin{array}{c}0.175 \\
\pm 0.001\end{array}$ & $\begin{array}{c}0.066 \\
\pm 0.001\end{array}$ & $\begin{array}{c}0.163 \\
\pm 0.001\end{array}$ & $\begin{array}{c}0.128 \\
\pm 0.001\end{array}$ \\
\hline Syringaresinol & $\begin{array}{c}0.077 \\
\pm 0.000\end{array}$ & $\begin{array}{c}0.081 \\
\pm 0.000\end{array}$ & $\begin{array}{c}0.091 \\
\pm 0.001\end{array}$ & $\begin{array}{c}0.068 \\
\pm 0.001\end{array}$ & $\begin{array}{c}0.097 \\
\pm 0.000\end{array}$ & $\begin{array}{c}0.066 \\
\pm 0.000\end{array}$ & $\begin{array}{c}0.060 \\
\pm 0.001\end{array}$ & $\begin{array}{c}0.067 \\
\pm 0.000\end{array}$ & $\begin{array}{l}0.102 \\
\pm 0.00\end{array}$ & $\begin{array}{c}0.103 \\
\pm 0.000\end{array}$ & $\begin{array}{c}0.092 \\
\pm 0.002\end{array}$ \\
\hline
\end{tabular}


Table 1. The phenolic compounds according to various ultrasonic thermal fusion treatment conditions of Acanthopanax koreanum stem (Continued)

$(\%, \mathrm{w} / \mathrm{w})$

\begin{tabular}{lccccccccccc}
\hline \hline $\begin{array}{l}\text { Phenolic } \\
\text { compounds }\end{array}$ & UAK-8 & UAK-9 & UAK-10 & UAK-11 & UAK-12 & UAK-13 & UAK-14 & UAK-15 & UAK-16 & UAK-17 & UAK-18 \\
\hline Quercetin & $\begin{array}{c}0.032 \\
\pm 0.000\end{array}$ & $\begin{array}{c}0.029 \\
\pm 0.000\end{array}$ & $\begin{array}{c}0.017 \\
\pm 0.000\end{array}$ & $\begin{array}{c}0.015 \\
\pm 0.000\end{array}$ & $\begin{array}{c}0.015 \\
\pm 0.000\end{array}$ & $\begin{array}{c}0.028 \\
\pm 0.000\end{array}$ & $\begin{array}{c}0.029 \\
\pm 0.000\end{array}$ & $\begin{array}{c}0.012 \\
\pm 0.000\end{array}$ & $\begin{array}{c}0.014 \\
\pm 0.000\end{array}$ & $\begin{array}{c}0.016 \\
\pm 0.000\end{array}$ & $\begin{array}{c}0.030 \\
\pm 0.000\end{array}$ \\
\hline $\begin{array}{l}\text { Total phenolic } \\
\text { compound }\end{array}$ & 4.413 & 5.282 & 4.799 & 4.903 & 4.701 & 4.240 & 2.870 & 5.135 & 4.985 & 3.767 & 4.616 \\
\hline
\end{tabular}

*UAK-8: 8 hours ultrasonic thermal fusion treated extract, UAK-9: 9 hours ultrasonic thermal fusion treated extract, UAK-10: 10 hours ultrasonic thermal fusion treated extract, UAK-11: 11 hours ultrasonic thermal fusion treated extract, UAK-12: 12 hours ultrasonic thermal fusion treated extract, UAK-13: 13 hours ultrasonic thermal fusion treated extract, UAK-14: 14 hours ultrasonic thermal fusion treated extract, UAK-15: 15 hours ultrasonic thermal fusion treated extract, UAK-16: 16 hours ultrasonic thermal fusion treated extract, UAK-17: 17 hours ultrasonic thermal fusion treated extract, UAK-18: 18 hours ultrasonic thermal fusion treated extract. Values represent the mean \pm S.D. $(n=3)$

\begin{tabular}{|c|c|c|c|c|c|c|c|c|c|c|}
\hline $\begin{array}{l}\text { Phenolic } \\
\text { compounds }\end{array}$ & UAK-19 & UAK-20 & UAK-21 & UAK-22 & UAK-23 & UAK-24 & UAK-36 & UAK-48 & UAK-60 & UAK-72 \\
\hline $\begin{array}{l}\text { Protocatechuic } \\
\text { acid }\end{array}$ & $\begin{array}{c}0.434 \\
\pm 0.000\end{array}$ & $\begin{array}{c}0.513 \\
\pm 0.003\end{array}$ & $\begin{array}{c}0.300 \\
\pm 0.001\end{array}$ & $\begin{array}{c}0.303 \\
\pm 0.002\end{array}$ & $\begin{array}{c}0.365 \\
\pm 0.001\end{array}$ & $\begin{array}{c}0.358 \\
\pm 0.003\end{array}$ & $\begin{array}{c}0.216 \\
\pm 0.003\end{array}$ & $\begin{array}{c}0.235 \\
\pm 0.002\end{array}$ & $\begin{array}{c}0.261 \\
\pm 0.001\end{array}$ & $\begin{array}{c}0.345 \\
\pm 0.002\end{array}$ \\
\hline $\begin{array}{l}\text { Eleutheroside } \\
\text { B }\end{array}$ & $\begin{array}{c}0.470 \\
\pm 0.004\end{array}$ & $\begin{array}{c}0.888 \\
\pm 0.005\end{array}$ & $\begin{array}{c}0.537 \\
\pm 0.001\end{array}$ & $\begin{array}{c}0.626 \\
\pm 0.002\end{array}$ & $\begin{array}{c}0.590 \\
\pm 0.001\end{array}$ & $\begin{array}{c}0.656 \\
\pm 0.002\end{array}$ & $\begin{array}{c}0.418 \\
\pm 0.005\end{array}$ & $\begin{array}{c}0.407 \\
\pm 0.002\end{array}$ & $\begin{array}{c}0.460 \\
\pm 0.002\end{array}$ & $\begin{array}{c}0.296 \\
\pm 0.002\end{array}$ \\
\hline Scopolin & $\begin{array}{c}0.292 \\
\pm 0.004\end{array}$ & $\begin{array}{c}0.380 \\
\pm 0.004\end{array}$ & $\begin{array}{c}0.266 \\
\pm 0.003\end{array}$ & $\begin{array}{c}0.236 \\
\pm 0.001\end{array}$ & $\begin{array}{c}0.310 \\
\pm 0.004\end{array}$ & $\begin{array}{c}0.323 \\
\pm 0.000\end{array}$ & $\begin{array}{c}0.310 \\
\pm 0.001\end{array}$ & $\begin{array}{c}0.296 \\
\pm 0.002\end{array}$ & $\begin{array}{c}0.109 \\
\pm 0.003\end{array}$ & - \\
\hline $\begin{array}{l}\text { Chlorogenic } \\
\text { acid }\end{array}$ & $\begin{array}{c}0.852 \\
\pm 0.005\end{array}$ & $\begin{array}{c}1.220 \\
\pm 0.008\end{array}$ & $\begin{array}{c}0.872 \\
\pm 0.003\end{array}$ & $\begin{array}{c}1.025 \\
\pm 0.004\end{array}$ & $\begin{array}{c}1.039 \\
\pm 0.001\end{array}$ & $\begin{array}{c}1.102 \\
\pm 0.003\end{array}$ & $\begin{array}{c}0.686 \\
\pm 0.003\end{array}$ & $\begin{array}{c}0.708 \\
\pm 0.001\end{array}$ & $\begin{array}{c}0.516 \\
\pm 0.015\end{array}$ & $\begin{array}{c}0.642 \\
\pm 0.005\end{array}$ \\
\hline $\begin{array}{l}\text { Eleutheroside } \\
\text { B1 }\end{array}$ & $\begin{array}{c}0.573 \\
\pm 0.005\end{array}$ & $\begin{array}{c}0.862 \\
\pm 0.010\end{array}$ & $\begin{array}{c}0.605 \\
\pm 0.001\end{array}$ & $\begin{array}{c}0.667 \\
\pm 0.002\end{array}$ & $\begin{array}{c}0.661 \\
\pm 0.008\end{array}$ & $\begin{array}{c}0.753 \\
\pm 0.025\end{array}$ & $\begin{array}{c}0.545 \\
\pm 0.003\end{array}$ & $\begin{array}{c}0.419 \\
\pm 0.007\end{array}$ & $\begin{array}{c}0.385 \\
\pm 0.001\end{array}$ & $\begin{array}{c}0.481 \\
\pm 0.006\end{array}$ \\
\hline Caffeic acid & $\begin{array}{c}0.154 \\
\pm 0.003\end{array}$ & $\begin{array}{c}0.492 \\
\pm 0.009\end{array}$ & $\begin{array}{c}0.276 \\
\pm 0.002\end{array}$ & $\begin{array}{c}0.146 \\
\pm 0.006\end{array}$ & $\begin{array}{c}0.128 \\
\pm 0.012\end{array}$ & $\begin{array}{c}0.133 \\
\pm 0.003\end{array}$ & $\begin{array}{c}0.342 \\
\pm 0.004\end{array}$ & $\begin{array}{c}0.098 \\
\pm 0.000\end{array}$ & $\begin{array}{c}0.185 \\
\pm 0.004\end{array}$ & $\begin{array}{c}0.302 \\
\pm 0.000\end{array}$ \\
\hline Eleutheroside E & $\begin{array}{c}1.105 \\
\pm 0.002\end{array}$ & $\begin{array}{c}1.646 \\
\pm 0.015\end{array}$ & $\begin{array}{c}0.882 \\
\pm 0.005\end{array}$ & $\begin{array}{c}1.235 \\
\pm 0.002\end{array}$ & $\begin{array}{c}1.212 \\
\pm 0.005\end{array}$ & $\begin{array}{c}1.289 \\
\pm 0.008\end{array}$ & $\begin{array}{c}0.832 \\
\pm 0.016\end{array}$ & $\begin{array}{c}0.965 \\
\pm 0.001\end{array}$ & $\begin{array}{c}1.101 \\
\pm 0.021\end{array}$ & $\begin{array}{c}1.227 \\
\pm 0.054\end{array}$ \\
\hline Sinapyl alcohol & $\begin{array}{c}0.165 \\
\pm 0.001\end{array}$ & $\begin{array}{c}0.166 \\
\pm 0.003\end{array}$ & $\begin{array}{c}0.165 \\
\pm 0.000\end{array}$ & $\begin{array}{c}0.137 \\
\pm 0.001\end{array}$ & $\begin{array}{c}0.123 \\
\pm 0.001\end{array}$ & $\begin{array}{c}0.110 \\
\pm 0.002\end{array}$ & $\begin{array}{c}0.065 \\
\pm 0.002\end{array}$ & $\begin{array}{c}0.065 \\
\pm 0.001\end{array}$ & $\begin{array}{c}0.054 \\
\pm 0.002\end{array}$ & $\begin{array}{c}0.039 \\
\pm 0.001\end{array}$ \\
\hline Rutin & $\begin{array}{c}0.158 \\
\pm 0.001\end{array}$ & $\begin{array}{c}0.275 \\
\pm 0.001\end{array}$ & $\begin{array}{c}0.161 \\
\pm 0.001\end{array}$ & $\begin{array}{c}0.193 \\
\pm 0.004\end{array}$ & $\begin{array}{c}0.199 \\
\pm 0.001\end{array}$ & $\begin{array}{c}0.270 \\
\pm 0.003\end{array}$ & $\begin{array}{c}0.262 \\
\pm 0.002\end{array}$ & $\begin{array}{c}0.185 \\
\pm 0.006\end{array}$ & $\begin{array}{c}0.180 \\
\pm 0.002\end{array}$ & $\begin{array}{c}0.215 \\
\pm 0.000\end{array}$ \\
\hline Hyperoside & $\begin{array}{c}0.119 \\
\pm 0.000\end{array}$ & $\begin{array}{c}0.196 \\
\pm 0.001\end{array}$ & $\begin{array}{c}0.119 \\
\pm 0.002\end{array}$ & $\begin{array}{c}0.139 \\
\pm 0.001\end{array}$ & $\begin{array}{c}0.157 \\
\pm 0.001\end{array}$ & $\begin{array}{c}0.175 \\
\pm 0.003\end{array}$ & $\begin{array}{c}0.202 \\
\pm 0.002\end{array}$ & $\begin{array}{c}0.123 \\
\pm 0.002\end{array}$ & $\begin{array}{c}0.135 \\
\pm 0.001\end{array}$ & $\begin{array}{c}0.160 \\
\pm 0.001\end{array}$ \\
\hline Isofraxidin & $\begin{array}{c}0.122 \\
\pm 0.000\end{array}$ & $\begin{array}{c}0.218 \\
\pm 0.001\end{array}$ & $\begin{array}{c}0.107 \\
\pm 0.001\end{array}$ & $\begin{array}{c}0.120 \\
\pm 0.001\end{array}$ & $\begin{array}{c}0.121 \\
\pm 0.001\end{array}$ & $\begin{array}{c}0.086 \\
\pm 0.001\end{array}$ & $\begin{array}{c}0.114 \\
\pm 0.002\end{array}$ & $\begin{array}{c}0.099 \\
\pm 0.000\end{array}$ & $\begin{array}{c}0.104 \\
\pm 0.005\end{array}$ & $\begin{array}{c}0.096 \\
\pm 0.001\end{array}$ \\
\hline Syringaresinol & $\begin{array}{c}0.085 \\
\pm 0.000\end{array}$ & $\begin{array}{c}0.115 \\
\pm 0.000\end{array}$ & $\begin{array}{c}0.083 \\
\pm 0.000\end{array}$ & $\begin{array}{c}0.132 \\
\pm 0.000\end{array}$ & $\begin{array}{c}0.090 \\
\pm 0.001\end{array}$ & $\begin{array}{c}0.105 \\
\pm 0.001\end{array}$ & $\begin{array}{c}0.101 \\
\pm 0.000\end{array}$ & $\begin{array}{c}0.152 \\
\pm 0.001\end{array}$ & $\begin{array}{c}0.143 \\
\pm 0.000\end{array}$ & $\begin{array}{c}0.092 \\
\pm 0.000\end{array}$ \\
\hline Quercetin & $\begin{array}{c}0.030 \\
\pm 0.000 \\
\end{array}$ & $\begin{array}{c}0.020 \\
\pm 0.001 \\
\end{array}$ & $\begin{array}{c}0.030 \\
\pm 0.000 \\
\end{array}$ & $\begin{array}{c}0.021 \\
\pm 0.000 \\
\end{array}$ & $\begin{array}{c}0.029 \\
\pm 0.000 \\
\end{array}$ & $\begin{array}{c}0.030 \\
\pm 0.000 \\
\end{array}$ & $\begin{array}{c}0.022 \\
\pm 0.000 \\
\end{array}$ & $\begin{array}{c}0.035 \\
\pm 0.001 \\
\end{array}$ & $\begin{array}{c}0.038 \\
\pm 0.001 \\
\end{array}$ & $\begin{array}{c}0.025 \\
\pm 0.000 \\
\end{array}$ \\
\hline $\begin{array}{l}\text { Total phenolic } \\
\text { compound }\end{array}$ & 4.324 & 6.661 & 4.171 & 4.688 & 4.747 & 5.082 & 3.788 & 3.476 & 3.356 & 3.644 \\
\hline
\end{tabular}

*UAK-19: 19 hours ultrasonic thermal fusion treated extract, UAK-20: 20 hours ultrasonic thermal fusion treated extract, UAK-21: 21 hours ultrasonic thermal fusion treated extract, UAK-22: 22 hours ultrasonic thermal fusion treated extract, UAK-23: 23 hours ultrasonic thermal fusion treated extract, UAK-24: 24 hours ultrasonic thermal fusion treated extract, UAK-36: 36 hours ultrasonic thermal fusion treated extract, UAK-48: 48 hours ultrasonic thermal fusion treated extract, UAK-60: 60 hours ultrasonic thermal fusion treated extract, UAK-72: 72 hours ultrasonic thermal fusion treated extract. Values represent the mean \pm S.D. $(n=3)$

$60,0.143 \%$ ) 그리고 22시간 초음파 열융합 처리(UAK-22, $0.132 \%)$ 의 순서로 함량이 높았다.
Isofraxidin은 15 시간 초음파 열융합 처리(UAK-15)에서 $0.175 \%$ 로 가장 함량이 높게 나타났고, 그 다음으로 4 시간 
초음파 열융합 처리(UAK-4, 0.166\%) 그리고 7시간 초음 파 열융합 처리(UAK-7, 0.165\%)의 순서로 함량이 높았다. Sinapyl alcohol은 12시간 초음파 열융합 처리(UAK-12)에 서 $0.230 \%$ 로 가장 함량이 높게 나타났으며, 그 다음으로 15 시간 초음파 열융합 처리(UAK- $15,0.182 \%)$ 그리고 13 시 간 초음파 열융합 처리(UAK-13,0.175\%)의 순서로 함량 이 높았다. 또한, 플라보노이드계 성분인 rutin, hyperoside, quercetin과 쿠마린계 성분인 scopolin, eleutheroside B1, isofracxidin 등은 초음파 열융합 처리에 의해서 성분의 변 화가 관찰되지 않았다.

이와 같은 결과로부터, 페닐프로파노이드계 생리활성 성분인 eleutheroside B (syringin)과 chlorogenic acid는 1시간 초음파 열융합 처리로 가장 높은 농도의 추출물을 얻을 수 있었다. 그러나, 총 페놀성 성분 함량과 오가피속 식 물의 대표적인 리그난계 생리활성 성분인 eleutheroside E 의 함유농도가 가장 높게 확인된 20시간이 섬오가피 줄 기의 초음파 열융합 처리 최적 조건이라고 사료된다.

섬오가피의 줄기를 초음파 열융합 처리한 결과, 총 페 놀성 성분 함량에 있어서는 20 시간 초음파 열융합 처리 조건(UAK-20)에서 $6.661 \%$ 로 가장 높았다. 또한, 오가피의 주성분이며, 생리활성 성분인 eleutheroside E도 20시간 초 음파 열융합 처리 조건(UAK-20)에서 $1.646 \%$ 로 가장 높았 다. 따라서, 섬오가피의 초음파 열융합 최적 처리 조건은 총 페놀성 성분 함량과 오가피속 식물의 대표적인 생리활 성 성분인 eleutheroside $\mathrm{E}$ 의 함유농도가 가장 높게 확인된 20 시간 초음파 열융합 처리 방법이라고 사료된다.

\section{ACKNOWLEDGEMENT}

This work was supported by Korea Institute of Planning and Evaluation for Technology in Food, Agriculture and Forestry (IPET) through Future Innovation Food Technology Development Program, funded by Ministry of Agriculture, Food and Rural Affairs (MAFRA) (119023-3).

\section{CONFLICT OF INTEREST}

The authors have declared no conflict of interest.

\section{REFERENCES}

Ahn J, Um MY, Lee H, Jung CH, Heo SH, Ha TY. Eleutheroside E, an active component of Eleutherococcus senticosus, ameliorates insulin resistance in type 2 diabetic $\mathrm{db} / \mathrm{db}$ mice. Evid
Based Complement Alternat Med. 2013. 2013: 934183.

An HJ, Nam YM, Yang BW, Park JD, Yook CS, Kim HC, Ko SK. The comparison of phytochemical components from the berry of Acanthopanax species. Kor J Pharmacogn. 2017. 48: 5-9.

An HJ, Yook CS, Kim HC, Ko SK. Measurement of characteristic phytochemical levels in different Acanthopanax Species by HPLC. Yakhak Hoeji. 2017. 61: 90-95.

Cho S, Cho M, Kim J, Kaeberlein M, Lee SJ, Suh Y. Syringaresinol protects against hypoxia / reoxygenation-induced cardiomyocytes injury and death by destabilization of HIF-1 $\alpha$ in a FOXO3-dependent mechanism. Oncotarget. 2015. 6: 43-55.

Choi J, Shin KM, Park HJ, Jung HJ, Kim HJ, Lee YS, Rew JH, Lee KT. Anti-inflammatory and antinociceptive effects of sinapyl alcohol and its glucoside syringin. Planta Med. 2004. 70: 1027 -1032 .

Chung BH, Kim S, Kim JD, Lee JJ, Baek YY, Jeoung D, Lee H, Choe J, Ha KS, Won MH, Kwon YG, Kim YM. Syringaresinol causes vasorelaxation by elevating nitric oxide production through the phosphorylation and dimerization of endothelial nitric oxide synthase. Exp Mol Med. 2012. 44: 191-201.

Gong X, Zhang L, Jiang R, Wang CD, Yin XR, Wan JY. Hepatoprotective effects of syringin on fulminant hepatic failure induced by D-galactosamine and lipopolysaccharide in mice. J Appl Toxicol. 2014. 34: 265-271.

He C, Chen X, Zhao C, Qie Y, Yan Z, Zhu X. Eleutheroside E ameliorates arthritis severity in collagen-induced arthritis mice model by suppressing inflammatory cytokine release Inflammation. 2014. 5: 1533-1543.

Jung MG, Do GM, Shin JH, Ham YM, Park SY, Kwon O. Acanthopanax koreanum Nakai modulates the immune response by inhibiting TLR 4-dependent cytokine production in rat model of endotoxic shock. Nutr Res Pract. 2013. 7: 460 -465 .

Kim J, Cho SY, Kim SH, Cho D, Kim S, Park CW, Shimizu T, Cho JY, Seo DB, Shin SS. Effects of Korean ginseng berry on skin antipigmentation and antiaging via FoxO3a activation. J Ginseng Res. 2017. 41: 277-283.

Korean Association of Herbal Medicine Professors. Herbal medicine. 1994. pp. 283-284. Yeong Lim Press. Seoul, Korea.

Korean Association of Pharmacognosy Professors. Herbal medicine. 2004. pp. 305-308. Korean Pharmaceutical Association. Seoul, Korea.

Ko SK. Oriental Medicine Pharmacognosy. 2016. pp. 128-129. Jin Young Press. Seoul, Korea. 
Lall N, Kishore N, Binneman B, Twilley D, Plessis-Stoman D, Boukes G, Hussein A. Cytotoxicity of syringin and 4methoxycinnamyl alcohol isolated from Foeniculum vulgare on selected human cell lines. Nat Prod Res. 2015. 29: 1752 -1756 .

Li C, Wang XY, Hu XW, Fang HT, Qiao SY. Determination of eleutheroside $\mathrm{B}$ in antifatigue fraction of Acanthopanax senticosus by HPLC. Zhongguo Zhong Yao Za Zhi. 2008. 33: 2800-2802.

Lim H, Min DS, Yun HE, Kim KT, Sun YN, Dat LD, Kim YH, Kim HP. Impressic acid from Acanthopanax koreanum, possesses matrix metalloproteinase-13 down-regulating capacity and protects cartilage destruction. J Ethnopharmacol. 2017. 209: 73-81.

Miyazawa M, Utsunomiya H, Inada K, Yamada T, Okuno Y, Tanaka H, Tatematsu M. Inhibition of Helicobacter pylori motility by $(+)$-syringaresinol from unripe Japanese apricot. Biol Pharm Bull. 2006. 29: 172-173.

Niu HS, Liu IM, Cheng JT, Lin CL, Hsu FL. Hypoglycemic effect of syringin from Eleutherococcus senticosus in streptozotocininduced diabetic rats. Planta Med. 2008. 74: 109-113.

Ovodov YS, Frolova GM, Nefedova MY, Elyakov GB. The glycosides of Eleutherococcus senticosus Max I. Isolation and some properties of eleutherosides B and E. Khim Prkrodn Soedin. 1996. 1:3-7.

Ovodov YS, Frolova GM. Triterpenoidal glycosides of Eleuterococcus sessiliflorus leaves II. Khim Prkrodn Soedin. 1971. 1: 618-622.

Park BY, Oh SR, Ahn KS, Kwon OK, Lee HK. (-)-Syringaresinol inhibits proliferation of human promyelocytic HL-60 leukemia cells via G1 arrest and apoptosis. Int Immunopharmacol. 2008. 8: 967-973.

Park MJ, Bae YS. Fermented Acanthopanax koreanum root extract reduces UVB- and $\mathrm{H}_{2} \mathrm{O}_{2}$-induced senescence in human skin fibroblast cells. J Microbiol Biotechnol. 2016. 26: 1224-1233.

Song YY, Li Y, Zhang HQ. Therapeutic effect of syringin on adjuvant arthritis in rats and its mechanisms. Yao Xue Xue Bao. 2010. 45: 1006-1011.

Wei C, Tan CK, Xiaoping H, Junqiang J. Acanthoic acid inhibits LPS-induced inflammatory response in human gingival fibroblasts. Inflammation. 2015. 38: 896-901.

Yook CS. Asia Saeng-Yak-Do-Gam. 1997. pp 359-362. Kyungwon media, Seoul. Korea.

Yook CS. Medicinal herbs of Acanthopanax in Asia. 2001. pp 1174. Kyungwon Media. Seoul. Korea.

Zhao LS, An Q, Qin F, Xiong ZL. Simulataneous determination of six constituents in the fruit of Acanthopanax sessiliflorus (Rupr. et maxim.) seem. by HPLC-UV. Nat Prod Res. 2014. 7: 500-502.

https://doi.org/10.15616/BSL.2020.26.4.319

Cite this article as: Kim SG, Yang BW, Lee JB, Kim $\mathrm{SH}$, Ko SK. Optimization of Conditions for High Concentration of Eleutheroside E and Chlorgenic Acid Components of Acanthopanax koreanum Stem Extract. Biomedical Science Letters. 2020. 26: 319-326. 